\title{
As Convenções brasileiras Contra a Dupla Tributação firmadas com países desenvolvidos e o Direito ao Desenvolvimento
}

\section{Márcio Ladeira Ávila. ${ }^{1}$}

RESUMO:

O trabalho traça as linhas gerais de como ocorre a influência da OCDE e da ONU na negociação, interpreta e aplicação das CCDTs brasileiras para ressaltar a falência dos mecanismos de incentivo fiscal presentes nas CCDTs celebradas entre países desenvolvidos e países em desenvolvimento, para trazer a crítica de que há a necessidade de independência na negociação, interpretação e aplicação das CCDTs brasileiras e, por fim, para propor como seria possível a construção de uma hipótese de concretização do direito ao desenvolvimento.

PALAVRAS-CHAVE: tributação internacional, desenvolvimento, interpretação, integração.

ABSTRACT:

This paper traces the outlines of the influence occurs as the OECD and the UN in negotiating, interpreting and applying the Brazilian CCDTs to highlight the failure of incentive mechanisms present in CCDTs tax treaties between developed and developing countries, to bring critical that there is a need for independence in the negotiation, interpretation and application of CCDTs Brazilian and, finally, to propose how it would be possible to build a case of realizing the right to development.

KEYWORDS: international taxation, development, interpretation, integration.

\section{Introdução}

O desenvolvimento das atividades econômicas internacionais não deve ter como empecilho a dupla tributação internacional ${ }^{2}$. Conforme ensina Antônio de Moura Borges, a questão não é apenas econômica, mas financeira, cultural, sócio-política, de justiça e equidade $^{3}$. Como bem coloca Victor Uckmar, é difícil etiquetar um produto "made in Italy" diante de tantos componentes e processos de fabricação ocorridos em diversos países ${ }^{4}$. Para o professor da Universidade de Gênova, esses produtos deveriam ser identificados como "made in the World".

O fenômeno da dupla tributação jurídica internacional surge porque dois ou mais Estados titulares de soberania tributária submetem o mesmo contribuinte, por idêntico objeto,

\footnotetext{
$1 \quad$ Mestre e Doutorando em Direito Internacional pela UERJ. Professor de Direito Tributário Internacional na Pós-Graduação da UFF. Consultor jurídico da PETROBRAS. Advogado no Rio de Janeiro.

2 De acordo com o saudoso Klaus Vogel, o Direito da Dupla Tributação é um ramo daquele que é comumente denominado de Direito Tributário Internacional. Cf. a clássica obra: Klaus Vogel on Double Taxation Conventions: a Commentary to the OECD-, UM- and US Model Conventions for de Avoidance of Doublé Taxation if Income and Capital with Particular Reference to German Treaty Practice. Deventer: Kluwer Law and Taxation Publishers, 1991, p. 3.

3 BORGES, Antônio de Moura. Convenções sobre Dupla Tributação Internacional entre Estados Desenvolvidos e Estados em Desenvolvimento. In: Revista Notícia do Direito Brasileiro. Nova Série. Brasília: Universidade de Brasília, LTr, 1996, p. 77.

UCKMAR, Victor. Introduzione. In: UKMAR, Victor (Org.). Corso Di Diritto Tributario Internazionale. Verona: Cedam-Padova, 2000, p. 10.
} 
contemporaneamente, a tributos similares ${ }^{5}$. Quando isso ocorre, o movimento de capitais e de pessoas, a transferência de tecnologia e o intercâmbio de bens e serviços ficam prejudicados.

O Direito Internacional Costumeiro não proíbe a dupla tributação ${ }^{6}$. Conseqüentemente, o meio encontrado pelo Direito Internacional para mitigá-la foi a introdução de regras que estabelecessem qual dos Estados envolvidos deveria abdicar do seu direito de tributar ${ }^{7}$.

A Convenção Contra a Dupla Tributação (CCDT), espécie de tratado internacional em matéria tributária, procura não apenas eliminar a dupla tributação jurídica internacional sobre rendimentos (v.g. royalties, juros e dividendos), mas também cuida de outros temas relevantes como a prevenção à evasão fiscal (v.g. combate ao treaty shopping e a cláusula de beneficiário efetivo) e a não-discriminação ${ }^{8}$.

Nos termos do Estatuto da Corte Internacional de Justiça (art. 38, al. a), a CCDT é fonte escrita do Direito Internacional. Vista sob o aspecto estático, é capaz de produzir direito objetivo. Contudo, interessa-nos seu aspecto dinâmico ou interpretativo, seja na perspectiva internacional ou na sua adequação com o ordenamento jurídico interno.

A interpretação da CCDT deve ser guiada pelas lições do Direito Internacional Público, dando-se especial enfoque para a Convenção de Viena sobre o Direito dos Tratados

$5 \quad$ A dupla tributação econômica difere da jurídica por ter diversidade de contribuintes, como ocorre com a tributação da pessoa jurídica no Estado "A" e dos sócios no Estado "B", ainda que o acréscimo patrimonial seja um só. As Convenções Contra a Dupla Tributação, em geral, não tratam da dupla tributação econômica internacional.

$6 \quad$ VOGEL, Klaus. Op Cit, p. 4. Como bem observado por Claudio Sacchetto, um ordenamento (jurídico) incompleto como é o internacional, não permite uma elaboração sistemática de suas fontes em termos exclusivamente "positivos". O costume internacional, constituído pelo comportamento constante e uniforme praticado pelos Estados, é fonte não escrita do direito internacional. SACHETO, Claudio. Las Fuentes del Derecho Internacional Tributario. In: UCKMAR, Victor (Org.). Curso de Derecho Tributario Internacional. Bogotá: Temis, 2003, p. 37 e 38.

A respeito do assunto, Ottmar Buhler já afirmava textualmente: "No se encuentra en los TDI uma cláusula general que declare materialmente ilícita la doble imposición; por el contrario, se trasluce el expresso mantenimiento de la doble imposición en materias menores cuando no se llega a un acuerdo sobre los mismos". BUHLER, Ottmar. Principios de Derecho Internacional Tributario. Madri: Editorial de Derecho Financiero, 1968, p. 79.

8 Jacob Dolinger ensina que a incorporação do tratado no sistema jurídico interno pelo critério do monismo moderado - prevalência do direito interno ou do direito internacional apenas em função da ordem cronológica de sua criação - vem sendo aceita pelo STF. Contudo, afirma que o art. 98 do Código Tributário Nacional (CTN), ao determinar a observância dos tratados "pelas leis que lhes sobrevenha", deve ser interpretado como regra específica e especialíssima do Direito Fiscal. DOLINGER, Jacob. Direito Internacional

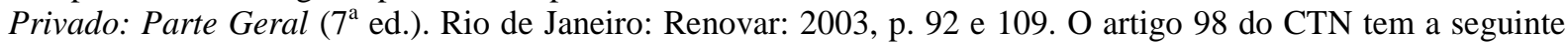
redação: "Os tratados e as convenções internacionais revogam ou modificam a legislação tributária interna, e serão observados pela que lhes sobrevenha". O saudoso Oscar Tenório defendia que o tratado, na qualidade de 
(CVDT) - que reproduz o costume internacional e foi recentemente ratificada pelo Brasil (Decreto Legislativo $n^{\circ} 496$, de 17 de julho de 2009 e Decreto $n^{\circ} 7.030$, de 14 de dezembro de 2009) ${ }^{9}$. Como ensina Klaus Vogel, as CCDTs são acordos internacionais e sua criação e efeitos devem ser determinados conforme as regras contidas na $\mathrm{CVDT}^{10}$.

No exercício de uma interpretação sistemática, pode-se afirmar que as CCDTs celebradas entre países em desenvolvimento (in casu, o Brasil) e países desenvolvidos devem de acordo com a Carta das Nações Unidas. Afinal, a tributação é a mais sustentável e benéfica fonte de financiamento para o desenvolvimento ${ }^{11}$. Conforme Franco Gallo, a tributação é o único instrumento de que dispõe o operador público para perseguir políticas sociais redistributivas e alocativas, além de servir para a promoção estável do crescimento cultural e econômico $^{12}$.

A Carta das Nações Unidas tem o propósito de promover a cooperação internacional para a solução de problemas internacionais de caráter econômico, social, cultural ou humanitário. Neste contexto, a Declaração sobre o Direito ao Desenvolvimento (aprovada pela Resolução no 41/128 da Assembléia Geral da ONU, em 1986) prevê em seu art. $3^{\circ}$ :

1. Os Estados têm a responsabilidade primária pela criação das condições nacionais e internacionais favoráveis à realização do direito ao desenvolvimento.

2. A realização do direito ao desenvolvimento requer pleno respeito aos princípios do direito internacional relativos às relações amistosas e cooperação entre os Estados em conformidade com a Carta das Nações Unidas.

3. Os Estados têm o dever de cooperar uns com os outros para assegurar o desenvolvimento e eliminar os obstáculos ao desenvolvimento. Os Estados deveriam realizar seus direitos e cumprir suas obrigações de modo tal a promover uma nova

fonte internacional, revelaria o melhor contingente para a formação de um direito uniforme. TENÓRIO, Oscar. Direito Internacional Privado (11 ${ }^{\mathrm{a}}$ ed.). Rio de Janeiro: Freitas Bastos, 1976, p. 85 e 88.

9 Duas observações devem ser colocadas. A primeira, é que não entraremos na discussão a respeito da dicotomia entre Direito Internacional Público e Direito Internacional Privado, sendo certo que a distinção é considerada obsoleta por parte da doutrina. Vide, dentre outros, o artigo de Fabio Morosini: Globalização e Novas Tendências em Filosofia do Direito Internacional: a Dicotomia entre Público e Privado da Cláusula de Estabilização. In: MARQUES, Cláudia Lima; DE ARAÚJO, Nadia (Org.). O Novo Direito Internacional Estudos em Homenagem a Erik Jayme. Rio de Janeiro: Renovar, 2005, p. 558-566. A segunda observação referese à distinção entre interpretação e aplicação dos tratados. De acordo com Georg Schwarzenberger, a interpretação é o processo de estabelecimento do aspecto legal e dos efeitos dos consentimentos alcançados pelas partes. Já a aplicação é o processo de determinação das conseqüências de determinada interpretação no caso concreto. SCHWARZENBERGER, Georg. International Law and Order. Nova Iorque: Praeger Publishers, 1971, p. 116.

$10 \quad$ VOGEL, Klaus. Op. Cit., p. 13.

11 Confira o interessante artigo "The UN is failing on international tax - so the OECD calls the shots". Disponível em: <http://taxjustice.blogspot.com/2008/06/un-is-failing-on-international-tax-so.html>. Acesso em 03 fev. 2010.

12 GALLO, Franco. Giustizia Sociale e Giustizia Fiscale tra Decentramento e Globalizzazione. In: TÔRRES, Heleno Taveira (Org.). Direito Tributário Internacional (vol. III). São Paulo: Quartier Latin, 2005 , p. 396. 
ordem econômica internacional baseada na igualdade soberana, interdependência, interesse mútuo e cooperação entre todos os Estados, assim como a encorajar a observância e a realização dos direitos humanos.

Por sua vez, o art. $4^{\circ}$ da Declaração determina que os Estados devam, individual e coletivamente, tomar medidas para formular as políticas internacionais de desenvolvimento, com vistas a facilitar a plena realização do direito ao desenvolvimento. Este é o arcabouço jurídico a ser utilizado como vetor para a análise crítica das CCDTs celebradas pelo Brasil.

\section{Breve exposição sobre a influência da OCDE e da ONU na negociação, interpretação e aplicação das CCDTs brasileiras}

Em 1921, a Liga das Nações iniciou os estudos a respeito da eliminação da dupla tributação internacional por intermédio de tratados bilaterais ${ }^{13}$. Como resultado, foi elaborado o primeiro modelo de Convenção bilateral (1928), o qual foi seguido pela Convenção Modelo do México (1943) e de Londres (1946). O trabalho desenvolvido pela Liga das Nações foi fundamental para a posterior evolução do tema, levada a cabo, principalmente, pela OCDE.

\section{A influência da OCDE nas CCDTs brasileiras}

No ano de 1955, após 70 (setenta) Convenções sobre a matéria já haverem sido assinadas entre Estados que hoje são membros da OCDE, o Conselho da então Organização Européia de Cooperação Econômica (OECE) adotou sua primeira Recomendação relativa à dupla tributação.

Após a Segunda Guerra Mundial, o aumento da interdependência econômica e da cooperação entre os Estados-membros da OECE demonstrou, de forma indubitável, a importância de medidas para prevenir a dupla tributação internacional. Isto ficou comprovado pelo aumento da rede de tratados internacionais em matéria tributária envolvendo os paísesmembros da OECE. 
Diante do cenário acima apresentado, tornou-se extremamente desejável a harmonização dessas Convenções através de uma interpretação uniforme. Neste intuito, o então Comitê Fiscal da OCDE (após 1971, Comitê de Assuntos Fiscais) começou a desenvolver um modelo de Convenção (draft convention) para resolver, efetivamente, o problema da dupla tributação existente entre os Estados-membros da Organização, o que resultou no conhecido relatório "Draft Double Taxation Convention on Income and Capital" $(1963)^{14}$.

O modelo de Convenção desenvolvido pelo Comitê Fiscal, além de ter facilitado as negociações bilaterais entre os Estados-membros, proporcionou certa harmonização entre as diversas Convenções bilaterais.

Conforme reconhecido pela própria OCDE, o impacto da Convenção Modelo de 1963 estendeu-se para além da Organização, sendo utilizada como documento básico de referência em negociações entre Estados signatários e não-signatários; entre Estados não-signatários entre si; e, no trabalho de outras organizações internacionais de nível regional ou mundial. O exemplo mais evidente da sua influência é o fato de ser utilizada como base para a versão original e posteriores revisões da Convenção Modelo das Nações Unidas sobre Dupla Tributação entre Países Desenvolvidos e em Desenvolvimento.

Fatores tais como o aumento das relações fiscais internacionais, a sofisticação dos negócios e a experiência obtida pelos Estados-membros da OCDE na negociação e aplicação das Convenções, levaram à revisão da Convenção Modelo de 1963. Em 1977, foi publicado um novo modelo de Convenção e Comentários e, em ambos os textos, passou a constar a posição dos Estados não-membros a respeito do tema.

13 RAAD, Kees Van. Introduction OECD Model Commentaries 2008. In Materials on International \& EC Tax Law 2009/2010 (9a. ed. - vol. 1.). Rotterdam: International Tax Center Leiden, 2009, p. 48-52.

14 O professor Michael J. McIntyre, da Wayne State University Law School, observa que o Modelo de Convenção em referência ocasionou o levantamento de barreiras substanciais ao exercício da jurisdição tributária no Estado da fonte, além de incentivar o planejamento tributário com base na forma em detrimento do conteúdo, o que certamente provoca perda de receita para os países em desenvolvimento. Confira: "The OECD published its draft model treaty in 1963. That convention drew heavily from the League's London Draft, but included additional features that favored capital exporting countries over capital importing countries. In form, the 1963 draft recognized the importance of sharing of revenue between the source and residence countries. Its practical effect, however, was to erect substantial barriers to the exercise of source jurisdiction and to afford multinational firms with major opportunities for tax minimizing strategies through its emphasis on legal form over economic substance". MCINTYRE, Michael J. Developing Countries and International Cooperation on Income Tax Matters: An Historical Review. Michigan: unpublished manuscript, 2005. Disponível em: <http://www.michielse.com/files/mcintyre intl_cooperation.pdf $>$. Acesso em: 03 mai. 2010. 
O Comitê de Assuntos Fiscais, ao reconhecer que a revisão da Convenção Modelo e dos Comentários se tornou um processo contínuo, adotou, em 1991, o conceito de "Convenção Modelo ambulatória" ("ambulatory Model Convention”), através de atualizações e emendas periódicas, sem a necessidade de se aguardar por uma revisão completa. Também ficou decidida a abertura para que Estados não-membros, outras partes interessadas e demais organizações internacionais pudessem contribuir no processo de revisão, de forma que a Convenção Modelo esteja em conformidade com a evolução das regras e princípios de tributação internacional.

O reconhecimento mundial do conteúdo da Convenção Modelo e sua incorporação na maioria das Convenções bilaterais ajudaram a fazer com que os seus Comentários se tornassem um guia comumente aceito para a negociação, interpretação e aplicação das CCDTs.

$\mathrm{Na}$ América Latina, existe um tratado internacional multilateral para evitar a dupla tributação, conhecido como Pacto Andino, celebrado entre os Estados membros (Bolívia, Colômbia, Equador, Peru e Venezuela), o qual tem profundas diferenças em relação ao Modelo OCDE, por adotar o princípio de tributação exclusiva no Estado da fonte ${ }^{15}$. O Brasil, assim como Argentina e Venezuela, afasta-se desse modelo pelo fato de firmar acordos com países industrializados. Neste sentido, terminam por adotar o Modelo OCDE.

O que será aqui sustentado é que, apesar das CCDTs brasileiras celebradas com países desenvolvidos seguirem o texto da Convenção Modelo da OCDE em quase toda a sua integralidade, a negociação, interpretação e aplicação desse mesmo texto não deve ser necessariamente igual ao que recomenda o texto e os Comentários da Organização. É certo que diversos estudos técnicos realizados pela OCDE podem e devem ser aproveitados pelos países em desenvolvimento. Contudo, o ponto crítico que se está a questionar é, principalmente, o fato da atual delimitação de competência tributária no âmbito das CCDTs terminar por garantir uma maior arrecadação de tributos para os Estados desenvolvidos.

Philip Baker afirma que o peso dos Comentários da OCDE diminui significativamente quando um ou ambos os Estados não são membros da OCDE, em que pese sua utilidade como

\footnotetext{
15 UCKMAR, Victor. I Tratati Internazionali in Materia Tributaria. In: UCKMAR, Victor (Org.). Corso
} di Diritto Tributario Internazionale. Verona: Cedam-Padova, 2000, p. 92 e 93. 
referência e meio de persuasão ${ }^{16}$. Apesar do permanente contato da OCDE com países nãomembros e a respeitável consideração com as questões dos países em desenvolvimento, fato é que a Organização em referência não representa a visão dos países em desenvolvimento ${ }^{17}$.

\section{A influência da ONU nas CCDTs brasileiras}

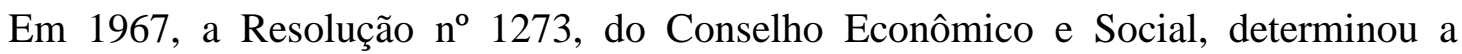
criação do Grupo Ad Hoc de Peritos em Tratados Internacionais entre Países Desenvolvidos e em Desenvolvimento, representado por diferentes regiões e sistemas fiscais (distribuição geográfica eqüitativa), o que foi levado a efeito no ano seguinte ${ }^{18}$. O objetivo era promover e facilitar a celebração de tratados que fossem aceitáveis por ambas as partes e que salvaguardassem os interesses arrecadatórios das partes envolvidas.

A Convenção Modelo da ONU, publicada em 1980, foi o resultado de mais de 10 (dez) anos de preparação pelo grupo de peritos. No mesmo ano, a Resolução no 1980, também do Conselho Econômico e Social, deu um título geral para o grupo (Grupo Ad Hoc de Peritos sobre Cooperação Internacional em Matéria Tributária) e aumentou sua composição de 20 (vinte) para 25 (vinte e cinco) membros, sendo 10 (dez) representantes da administração tributária de países desenvolvidos e 15 (quinze) de países em desenvolvimento ou de economia em transição. O mandato do Grupo Ad Hoc também foi ampliado para compreender a cooperação internacional em matéria tributária e, por essa razão, passou a poder examinar assuntos como preços de transferência, assistência mútua para cobrança de débitos, abusos na utilização de tratados (treaty shopping) e tributação do comércio eletrônico.

16 BAKER, Philip. Double Taxation Conventions and International Tax Law. Londres: Sweet \& Maxwell, 1994, p. 31. De acordo com Luís Eduardo Schoueri, as recomendações da OCDE não têm efeito vinculante, já que o Brasil não é membro da Organização. Por outro lado, ressalta que "se o País se dispõe a assinar um acordo segundo o modelo da OCDE, parece válido - a não ser que as circunstâncias indiquem o contrário - supor que ambas as partes conheciam aquele modelo e, portanto, seus comentários". SCHOUERI, Luís Eduardo. Preços de Transferência no Direito Tributário Brasileiro (2a ed.). São Paulo: Dialética, 2006, p. 261.

17 Neste sentido, vide: "Developing the International Dialogue on Taxation. A Joint Proposal by the Staffs of the IMF, OECD and World Bank". Disponível em: <http://www.imf.org/external/np/fad/itd/2002/031302.htm>. Acesso em: 07 fev. 2010. No mesmo sentido, vide o artigo "Developing Countries and International Cooperation on Income Tax Matters: An Historical Review", do professor Michael J. McIntyre (Wayne State University Law School). Michigan: unpublished manuscript, 2005. Disponível em: http://www.michielse.com/files/mcintyre_intl_cooperation.pdf. Acesso em: 03 mai. 2010.

18 Disponível em: 〈http://www.un.org/esa/ffd/tax/overview.htm〉. Acesso em: 24 abr. 2010. 
Através da Resolução $\mathrm{n}^{\mathrm{o}}$ 2.004/69, de 11 de novembro de 2004, o Conselho Econômico e Social renomeou pela segunda vez o grupo, que passou a ter a atual denominação: Comitê de Peritos sobre Cooperação Internacional em Matéria Tributária.

Apesar dos trabalhos desenvolvidos pela ONU procurarem privilegiar o princípio da territorialidade em matéria de tributação internacional ${ }^{19}$, eles não têm provocado o impacto a que se propõem ${ }^{20}$. Dentre os motivos que reduzem a importância dos estudos da ONU sobre a matéria, destacamos o fato de muitas das disposições de sua Convenção Modelo estão fundamentadas na Convenção Modelo da OCDE, elaborada por países desenvolvidos ${ }^{21}$. Como se isso não bastasse, a ONU tem se limitado, basicamente, a atualizar sua Convenção Modelo, em que pese o mandato do Comitê ser amplo o suficiente para discutir outros temas igualmente relevantes.

Ademais, os recursos financeiros destinados pela ONU para o desenvolvimento dos trabalhos parecem ser bastante limitados, a ponto da citada Resolução no 2004/69 afirmar expressamente que os encontros anuais do Comitê não poderão ultrapassar 5 (cinco) dias, diante dos recursos existentes. Enquanto isso, o Comitê de Assuntos Fiscais da OCDE promove mais de 60 (sessenta) encontros por ano, em base multilateral e regional.

$\mathrm{Na}$ verdade, a ONU deve concentrar seus esforços no estudo da legitimação para maior alocação de tributos (leia-se: aumento de receita nas operações internacionais) nos países em desenvolvimento. É necessário que as resoluções da ONU sobre a matéria sejam standards de comportamento internacional, de forma a moldar o direito internacional costumeiro e cristalizar, a longo prazo, os princípios gerais emergentes do direito internacional $^{22}$.

19 Heleno Taveira Torres afirma textualmente que "O Modelo da ONU (the UN Model), publicado em 1980, privilegia o princípio da territorialidade, em face do análogo Modelo da OCDE, constituindo, de certa forma, um compromisso de relacionamento congruente entre aquele princípio e o da tributação da renda mundial - o da universalidade". Pluritributação Internacional sobre as Rendas de Empresas (2a ed.). São Paulo: RT, 2001, p. 497 e 498.

20 Nesse sentido, vide o artigo de Dries Lesage, "Taxation and the 2008 UN Follow-Up on Financing for Development: Policy Recommendations". Disponível em: <http://www.taxjustice.net/cms/upload/pdf/Doha_and_tax_0806_Dries_Lesage.pdf>. Acesso em: 24 abr. 2010.

21 A presente afirmação não é mera constatação. O próprio item 45 da Convenção Modelo da ONU (parte introdutória, xxiv) afirma isso literalmente. Vide: 〈http://www.un.org/esa/ffd/tax/>. Acesso em: 06 jun. 2010.

${ }_{22}$ TRINDADE, Antônio Augusto Cançado. Direito das Organizações Internacionais (3 ${ }^{\mathrm{a}}$ ed.). Belo Horizonte: Del Rey, 2003, p. 42 , 43, 46, 47 e 74. O doutrinador considera incompleto, nos dias atuais, o artigo 38 do Estatuto da Corte Internacional de Justiça, que trata das fontes do direito internacional, por continuar silencioso quanto às resoluções das organizações internacionais. 
Antônio Augusto Cançado Trindade, ao estudar a natureza jurídica e efeitos dos atos da ONU, afirma que determinadas resoluções requerem certo tipo de ação visando resultados específicos $^{23}$. Ainda de acordo com o doutrinador, quando determinadas resoluções de um organismo internacional estão intimamente vinculadas entre si, como partes de um processo contínuo no tempo, é possível "nelas identificar um conteúdo mais específico, refletindo uma opinio juris de consenso generalizado". A interpretação favorável ao Estado em desenvolvimento deve fazer parte da opinio iuris, ou seja, "pelo entendimento, pela convicção de que assim se procede por ser necessário, correto, justo e, pois, de bom direito" 24 .

Para Enrique Ricardo Lewandowski, sob um ponto de vista mais abrangente, todos os órgãos da ONU encontram-se, em termos práticos, comprometidos com a defesa e promoção dos direitos humanos ${ }^{25}$. Celso de Albuquerque Mello entende que as resoluções aprovadas pelos órgãos da ONU têm o efeito estrito de recomendação, mas acabam por ter o apoio dos governos e terminam por serem obrigatórias, o que conduz os Estados a seguirem este procedimento e procurarem apoio político para elas $^{26}$. Conclui o doutrinador que as recomendações obrigatórias são a origem do que os norte-americanos denominaram de soft law.

Integrantes do Fundo Monetário Internacional, Banco Mundial, Banco Interamericano de Desenvolvimento e OCDE criaram o "International Tax Dialogue" (ITD), coerente com a Conferência da ONU sobre o Financiamento do Desenvolvimento ${ }^{27}$. Ora, se o papel das organizações internacionais é fundamental para o alcance desse fim, então, que a ONU seja a principal responsável por esse movimento, não se limitando ao mero papel de coadjuvante.

23 TRINDADE, Antônio Augusto Cançado. Op. Cit., p. 39. As resoluções da ONU sobre tributação internacional seguem justamente essa linha, pois tratam das ações de um grupo de peritos com vistas ao atendimento das necessidades dos países em desenvolvimento e dos países com economias em transição.

24 REZEK, José Francisco. Direito Internacional Público: Curso Elementar. São Paulo: Saraiva, 2002, p. 115 .

LEWANDOWSKI, Enrique Ricardo. Proteção dos Direitos Humanos na Ordem Interna e Internacional. Rio de Janeiro: Forense, 1984, p. 109. Na mesma linha, Fabiana de Oliveira Godinho defende que a busca do respeito aos direitos e liberdades humanas depende da harmonização das ações dos Estados e que a ONU é a instituição cujos objetivos residem na cooperação entre as nações, visando à paz, à segurança e ao desenvolvimento social mundial. GODINHO, Fabiana de Olibeira. A Proteção Internacional dos Direitos Humanos. Belo Horizonte: Del Rey, 2006, p. 7.

26 MELLO, Celso D. de Albuquerque. Direito Internacional da Integração. Rio de Janeiro: Renovar, 1996, p. 60 e 61. No mesmo sentido, Klaus Vogel entende que a Convenção Modelo da OCDE e os respectivos Comentários pertencem à noção de soft Law. Op. Cit., p. 34.

27 Developing the International Dialogue on Taxation. A Joint Proposal by the Staffs of the IMF, OECD and World Bank. Disponível em: <http://www.imf.org/external/np/fad/itd/2002/031302.htm>. Acesso em: 07 
A questão que ainda fica sem resposta é saber se existe um consenso generalizado na comunidade jurídica internacional sobre a necessidade de atendimento, por intermédio das Convenções contra a Dupla Tributação, dos anseios dos países em desenvolvimento e daqueles com economias em transição,

Por todo o exposto, na forma como hoje se encontram, entendemos que a Convenção Modelo da ONU e os estudos correlatos pouco têm contribuído para a negociação, interpretação e aplicação das CCDTs brasileiras.

\section{A falência dos atuais mecanismos de incentivo fiscal presentes nas CCDTs celebradas entre países desenvolvidos e países em desenvolvimento}

As CCDTs celebradas entre países desenvolvidos e países em desenvolvimento costumam prever um dos seguintes incentivos tributários em seus textos: tax sparring (crédito fictício) e matching credit (crédito presumido).

Alberto Xavier explica com clareza as duas modalidades ${ }^{28}$ :

O matching credit ou crédito de imposto presumido (lump-sum tax credit, pauschale Steueranrechnung) consiste na atribuição de um crédito mais elevado do que o que resultaria da aplicação da alíquota convencional ou de direito comum em vigor no país da fonte. [...].

O tax sparing ou crédito de imposto fictício (shadowing, phantom tax, notional tax, ou imputação especial por isenção de imposto) consiste na atribuição de um crédito correspondente ao imposto que teria sido pago no país de origem se não fossem as medidas de exorenação com que neste se pretendeu incentivar o investimento no exterior.

Referidos incentivos visam incrementar os investimentos dos países exportadores de capital nos países em desenvolvimento. Não importam, de forma direta, em maior arrecadação para o Estado da fonte, mas em renúncia de parte ou todo o tributo devido ao Estado de residência. A medida, portanto, é meramente de fomento.

fev. 2010. A Conferência de Monterrey sobre o financiamento do desenvolvimento contém diversas referências a questões tributárias internacionais.

${ }^{28}$ XAVIER, Alberto. Direito Tributário Internacional do Brasil (6 $6^{\mathrm{a}}$ ed.). Rio de Janeiro: Forense, 2004, p. 823 e 824. 
O Brasil adota uma política favorável à adoção da cláusula de tax sparring nas CCDTs que vierem a ser celebradas com países membros do Mercado Comum do Sul (MERCOSUL). O art. $2^{\circ}$ da IN SRF $n^{\circ} 244 / 02$ prevê:

\begin{abstract}
Art. $2^{\circ}$ Nas Convenções destinadas a evitar a dupla tributação da renda, a serem firmadas pelo Brasil com países integrantes do Mercado Comum do Sul (Mercosul), será incluída cláusula prevendo a concessão de crédito do imposto de renda sobre lucros e dividendos recebidos por pessoa jurídica domiciliada no Brasil que deveria ser pago no outro país signatário, mas que não haja sido em decorrência de lei de vigência temporária de incentivo ao desenvolvimento econômico, nacional, regional ou setorial.

Parágrafo único. O crédito referido no caput, observadas as demais condições gerais de concessão e outras que vierem a ser estabelecidas em legislação específica, somente será admitido quando os lucros ou dividendos distribuídos provierem, diretamente, de atividade desenvolvida no país estrangeiro signatário, relativa aos setores:

I - industrial, exceto da indústria de cigarro e bebidas em geral, inclusive os concentrados destas;

II - agrícola, de florestamento ou pesqueira.
\end{abstract}

No caso, a medida se justifica porque o Brasil é, nitidamente, o país mais desenvolvido do bloco e tem interesse em incrementar os investimentos nos demais países membros.

Ocorre que os países desenvolvidos relutam, durante as negociações de CCDTs com países não desenvolvidos, em conceder os mencionados incentivos. Esse fato se agravou diante da recente crise financeira mundial. Faz-se necessário, portanto, que os países em desenvolvimento lancem mão de novos argumentos jurídicos não apenas para atrair o investimento estrangeiro, mas também para garantir uma maior arrecadação para o Estado da fonte, de maneira que a desigualdade existente seja reconhecida na prática.

\title{
Análise crítica: necessidade de independência na negociação, interpretação e aplicação das CCDTs brasileiras
}

Enquanto os países exportadores de capital enfatizam a tributação internacional baseada no princípio da residência, os importadores de capital procuram reforçar o princípio da fonte, tendo em vista quase não possuírem rendimentos derivados do exterior auferidos por seus residentes ${ }^{29}$. Ainda que a classificação dos países quanto ao seu grau de desenvolvimento

29 Para Michael J. Graetz, professor da Universidade de Yale, as regras de residência derivam do exercício da soberania e jurisdição sobre seus residentes e cidadãos, enquanto as regras de fonte atentam, 
seja ampla e imprecisa, certo é que os países em desenvolvimento precisam dos países desenvolvidos para a obtenção de tecnologia e conhecimento.

Klaus Vogel entende que todos os países em desenvolvimento apresentam em comum a determinação de recuperar ou promover o crescimento de suas economias, dentre outras medidas, com a exportação dos produtos de que dispõem, para os países desenvolvidos, e com a importação, destes países, de capitais e tecnologia ${ }^{30}$.

Nesse contexto, torna-se necessário distinguir, por exemplo, a relação existente entre os Estados-Membros da OCDE, cujas nações são majoritariamente ricas e exportadoras de capital - a Organização também é conhecida como "Grupo dos Ricos”, já que seus integrantes produzem mais da metade da riqueza do mundo - e a existente entre países desenvolvidos e em desenvolvimento ${ }^{31}$. Para Pedro M. Herrera, os países em desenvolvimento apresentam claras peculiaridades a partir da perspectiva da justiça na atribuição do poder de $\operatorname{tributar}^{32}$. Não é possível interpretar uma Convenção firmada entre partes desiguais da mesma forma como sucede entre partes semelhantes.

É pouco provável que um Estado desenvolvido aceite firmar uma Convenção bilateral segundo o Modelo do Grupo Andino, que, com uma única exceção, adota tributação com exclusividade no Estado da fonte ${ }^{33}$. Do mesmo modo, uma Convenção que dê grande prioridade ao critério da residência (modelo OCDE) não interessa a um Estado em

geralmente, para a identificação do local geográfico onde ocorrem as atividades econômicas ou arranjos financeiros geradores de renda. GRAETZ, Michael J. Foundations of International Income Taxation. Foundation Press: Nova Iorque, 2003, p. 76. Devemos observar, contudo, que o direito norte-americano é reconhecidamente isolado na utilização da cidadania como regra de conexão para determinação da residência fiscal.

$30 \quad$ VOGEL, Klaus. Importância do Direito Tributário Internacional para os Países em Desenvolvimento. In: TAVOLARO, Agostinho Toffoli; MACHADO, Brandão; MARTINS, Ives Gandra da Silva (Org.). Estudos em Homenagem a Gilberto de Ulhôa Canto..Rio de Janeiro: Forense, 1998, p. 471.

31 A preocupação dos Estados-membros da OCDE é desenvolver um modelo de Convenção que sirva, basicamente, para negociarem entre si. Como existe uma relativa igualdade econômica entre os Estados signatário, a distinção quanto ao fluxo de capital entre Estado-fonte e Estado-residência não é tão acentuada, já que ambos são, simultaneamente, importadores e exportadores de capital. Apenas evidenciando ainda mais a presente constatação, Karen B. Brown afirma que a OCDE não tem levado em consideração a posição dos países em desenvolvimento na elaboração de seus relatórios. BROWN, Karen B. Harmful Tax Competition: The OECD View, 32 Geo. Wash. J. Int`l L. \& Econ. 311, 313-314, 316-319 (1999). In: GRAETZ, Michael J. Foundations of Internacional Income Taxation. Nova Iorque: Foundation Press, p. 528.

32 MOLINA, Pedro M. Herrera. Convenios de Doble Imposición y Derecho Comunitário. Madri: Ministerio de Economía y Hacienda - Instituto de Estudios Fiscales, 2009, p. 94.

33 BORGES, Antônio de Moura. Convenções sobre Dupla Tributação Internacional entre Estados Desenvolvidos e Estados em Desenvolvimento. In: Revista Notícia do Direito Brasileiro. Nova Série. Brasília: Universidade de Brasília, LTr, 1996, p. 74 e 75. 
desenvolvimento. Há que se chegar a um meio termo capaz de estancar a renúncia de receita decorrente da atual estrutura das Convenções brasileiras sobre bitributação ${ }^{34}$.

Antônio de Moura Borges afirma não haver argumentos que conduzam ao entendimento de que a tributação deva ser realizada, com exclusividade, ou no Estado de residência, ou no Estado da fonte, embora existam fortes argumentos que apontam este último Estado como devendo ter prioridade em tal atividade ${ }^{35}$. Tendo em vista que, nas relações firmadas entre Estados desenvolvidos e Estados em desenvolvimento, este último figura, predominantemente, como Estado da fonte, significa dizer que tem prioridade na tributação do rendimento.

A afirmação acima é muito feliz, pois nos leva à conclusão de que o Estado da fonte deve ser titular, no mínimo, de competência tributária cumulativa quando da celebração de Convenções sobre Bitributação.

Conforme ensina o saudoso Celso de Albuquerque Mello, as empresas transnacionais são mais um ator da sociedade internacional que, à semelhança das organizações internacionais, "atuam tanto em favor do fortalecimento do Estado da matriz, como também minam o poder dos Estados em que atuam, principalmente, quando estes são subdesenvolvidos, isto é, a quase totalidade dos que compõem a sociedade internacional" ${ }^{36}$.

O direito ao desenvolvimento surge como divisor de águas no debate sobre a repartição da competência tributária entre Estados desenvolvidos e Estados em desenvolvimento, devendo ser o norte na negociação e celebração de futuras CCDTs, além de servir como vetor interpretativo e de aplicação das CCDTs em vigor. Para José Casalta Nabais, à semelhança do que acontece com o mínimo de existência (físiológico e cultural) dos indivíduos, deve-se levar em consideração também, no que concerne às necessidades do Estado, a existência de um nível de gastos abaixo do qual o Estado seria incapaz de cumprir as suas funções mais elementares ${ }^{37}$. Conclui o doutrinador ser essa a razão pela qual o Estado

\footnotetext{
34 Naturalmente, a presente afirmação também é válida para outros países que figuram, predominantemente, como Estado da fonte (ou seja, países em desenvolvimento).

BORGES, Antônio de Moura. Delimitação da Competência Tributária Internacional em Matéria de Impostos sobre a Renda e o Capital. In: Revista Fórum de Direito Tributário $n^{o}$ 25. Belo Horizonte: Fórum, 2007, p. 117.

36 MELlO, Celso D. de Albuquerque. Direito Internacional da Integração. Rio de Janeiro: Renovar, 1996, p. 14 e 15.

37 NABAIS, José Casalta O Dever Fundamental de Pagar Impostos. Coimbra: Almedina, 2004, p. 216.
} 
tem o direito de impor e cobrar os impostos necessários ao cumprimento daquelas tarefas que, independentemente do lugar e tempo, indiscutivelmente lhes correspondem.

A necessidade de conciliar (a) o papel da ONU no estudo das CCDTs; (b) o direito ao desenvolvimento; e, (c) a releitura das Convenções brasileiras sobre a matéria, parece poder ser inferida, também, da seguinte afirmação de José Cretella Neto ${ }^{38}$ :

\begin{abstract}
A promoção do desenvolvimento não se dá apenas por meio da edição de normas de DIP obrigatórias para os Estados, cuja finalidade seja incidir diretamente sobre os processos de desenvolvimento dos países mais pobres, nem por meio da criação de importantes instituições internacionais, como a União Européia e a OCDE. Referimo-nos especialmente à realização de conferências, bem como à preparação de estudos e à elaboração de diretrizes e propostas concretas, promovidas pelos Estados ou organizações internacionais, em especial pela ONU, para favorecer a formação de um consenso internacional sobre a premente necessidade de superar o subdesenvolvimento, por meio de modelos econômicos não necessariamente idênticos, mas adequados a cada Estado, conforme suas necessidades, história e valores culturais.
\end{abstract}

É importante lembrar que a posição aqui defendida protege o interesse público brasileiro de uma renúncia tributária injustificada, mas não prejudica os interesses dos investidores estrangeiros, pois quando o tributo for pago no Brasil, representará um crédito (tax credit) a ser compensado no Estado de residência. Sob o ponto de vista econômico, o contribuinte pagará o mesmo montante, mas repartirá esse pagamento entre os Estados da fonte e de residência, ao invés de recolher o tributo apenas para este último.

A negociação, interpretação e aplicação das CCDTs brasileiras devem ter como norte o fato do Brasil ser um país em desenvolvimento e predominantemente importador de capital. Devem ser desenvolvidos instrumentos jurídicos capazes de atender ao interesse público brasileiro.

\title{
Hipótese de concretização do direito ao desenvolvimento
}

No presente item, apresentaremos uma hipótese de concretização do direito ao desenvolvimento que pode ser futuramente aplicada nas Convenções brasileiras Contra a Dupla Tributação firmadas com países desenvolvidos. Esse primeiro passo, longe de ter

38 CRETELLA NETO, José. Teoria Geral das Organizações Internacionais (2 ${ }^{\mathrm{a}}$ ed.). São Paulo: Saraiva, 2007, p. 434. 
caráter de definitividade, poderá servir como insumo em futuros debates no meio acadêmico e na prática jurídica.

O lucro das empresas, naturalmente, é o mais representativo tipo de rendimento presente nas Convenções Contra a Dupla Tributação (art. $7^{\circ}$ ). Tradicionalmente, essa espécie de rendimento pertence à tributação exclusiva do Estado de residência, até o momento em que é caracterizada a presença de estabelecimento permanente, como pode ser visualizado a seguir:

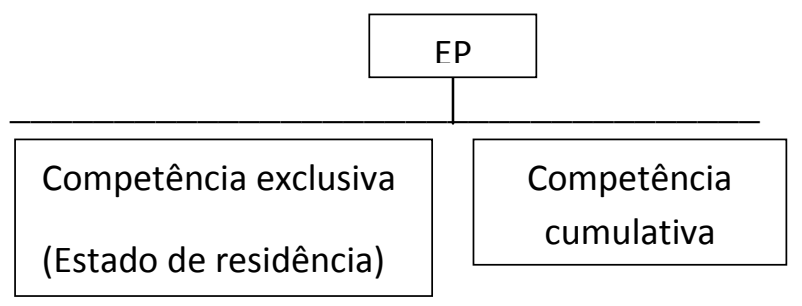

Entendemos que a competência do Estado de residência pode deixar de ser exclusiva, passando a ser cumulativa, ainda na hipótese de inexistência de estabelecimento permanente. O motivo é muito simples: o país em desenvolvimento, na qualidade de importador de capital, quase nunca tributará a renda na qualidade de Estado de residência (país exportador de capital). Por sua vez, o país desenvolvido, na qualidade de exportador de capital, quase sempre tributará a renda auferida no Estado da fonte.

Não estamos defendendo a falência do conceito de estabelecimento permanente quanto ao lucro das empresas, mas ele acaba sendo mais razoável entre partes iguais (Convenções celebradas apenas entre Estados desenvolvidos, ou, somente entre Estados em desenvolvimento). Contudo, Convenções entre partes desiguais não podem admitir que o Estado em desenvolvimento renuncie receita em favor do Estado desenvolvido. Não há fundamento ético, jurídico ou moral que justifique o atual estado de coisas. Outrossim, a cooperação internacional e o dever de solidariedade devem servir como norte na conduta entre Estados soberanos desiguais.

\section{Conclusões}

O presente artigo procurou demonstrar que as atividades de negociação, interpretação e aplicação das CCDTs brasileiras celebradas com países desenvolvidos possuem diversas 
particularidades que as distinguem das pactuadas entre os países membros da OCDE. Assim, propõe-se a seguinte hipótese geral: em que pese as CCDTs brasileiras se basearem na Convenção Modelo da OCDE, a sua negociação, interpretação e aplicação deve ter como premissa o fato do Brasil ser um país em desenvolvimento e predominantemente importador de capital.

Entendemos que a competência do Estado de residência para tributar o lucro das empresas pode deixar de ser exclusiva, passando a ser cumulativa. A posição aqui defendida protege o interesse público brasileiro de uma renúncia tributária injustificada, mas não prejudica os interesses dos investidores estrangeiros, pois quando o tributo for pago no Brasil, representará um crédito (tax credit) a ser compensado no Estado de residência. Sob o ponto de vista econômico, o contribuinte pagará o mesmo montante, mas repartirá esse pagamento entre os Estados da fonte e de residência, ao invés de recolher o tributo apenas para este último.

Devem-se buscar alternativas que assegurem, no mínimo, uma competência tributária cumulativa para o Estado da fonte, caso este seja um país em desenvolvimento. O direito ao desenvolvimento é o norte no presente debate e deve servir como parâmetro na negociação e celebração das CCDTs, além de servir como vetor interpretativo nas Convenções em vigor.

O Comitê de Peritos da ONU sobre Cooperação Internacional em Matéria Tributária deva buscar a maior independência possível em relação à Convenção Modelo da OCDE, elaborada por países desenvolvidos. Ademais, deve ir além da mera atualização de sua Convenção Modelo, passando a debater outros temas igualmente relevantes.

Outrossim, a ONU deveria alocar maiores recursos financeiros para o desenvolvimento dos trabalhos sobre a matéria, aumentando, conseqüentemente, o número de encontros do Comitê. A Organização deve concentrar seus esforços no estudo da legitimação da maior alocação de tributos (leia-se: aumento de receita) nos países em desenvolvimento. É necessário que as suas resoluções sobre a matéria sejam standards de comportamento internacional, de forma a moldar o direito internacional costumeiro e cristalizar, a longo prazo, os princípios gerais emergentes do direito internacional. Apenas dessa maneira, a ONU poderá contribuir para a interpretação e aplicação das CCDTs brasileiras.

\section{Bibliografia}


BAKER, Philip. Double Taxation Conventions and International Tax Law. Londres: Sweet \& Maxwell, 1994.

BORGES, Antônio de Moura. Convenções sobre Dupla Tributação Internacional entre Estados Desenvolvidos e Estados em Desenvolvimento. In: Revista Notícia do Direito Brasileiro. Nova série. Brasília: Universidade de Brasília, LTr, 1996.

- Delimitação da Competência Tributária Internacional em Matéria de Impostos sobre a Renda e o Capital. In: Revista Fórum de Direito Tributário $n^{o} 25$. Belo Horizonte: Fórum, 2007.

BROWN, Karen B. Harmful Tax Competition: The OECD View, 32 Geo. Wash. J. Int`1 L. \& Econ. 311, 313-314, 316-319 (1999). In Foundations of Internacional Income Taxation.

GRAETZ, Michael J. Nova Iorque: Foundation Press.

BUHLER, Ottmar. Principios de Derecho Internacional Tributario. Madri: Editorial de Derecho Financiero, 1968.

CRETELLA NETO, José. Teoria Geral das Organizações Internacionais (2a ed.). São Paulo: Saraiva, 2007.

Developing the International Dialogue on Taxation. A Joint Proposal by the Staffs of the IMF, OECD and World Bank. Disponível em: < http://www.imf.org/external/np/fad/itd/2002/031302.htm>. Acesso em: 07 fev. 2010.

DOLINGER, Jacob. Direito Internacional Privado: Parte Geral ( $7^{\mathrm{a}}$ ed.). Rio de Janeiro: Renovar: 2003.

GALLO, Franco. Giustizia Sociale e Giustizia Fiscale tra Decentramento e Globalizzazione. In: TÔRRES, Heleno Taveira (Org.). Direito Tributário Internacional (vol. III). São Paulo: Quartier Latin, 2005.

GODINHO, Fabiana de Olibeira. A Proteção Internacional dos Direitos Humanos. Belo Horizonte: Del Rey, 2006.

GRAETZ, Michael J. Graetz. Foundations of International Income Taxation. Foundation Press: Nova Iorque, 2003.

LESAGE, Dries. Taxation and the 2008 UN Follow-Up on Financing for Development: Policy Recommendations. Disponível em: $<$ http://www.taxjustice.net/cms/upload/pdf/Doha_and_tax_0806_Dries_Lesage.pdf $>$. Acesso em: 03 jun. 2010. 
LEWANDOWSKI, Enrique Ricardo. Proteção dos Direitos Humanos na Ordem Interna e Internacional. Rio de Janeiro: Forense, 1984.

MCINTYRE. Michael J. Developing Countries and International Cooperation on Income Tax Matters: An Historical Review. Michigan: unpublished manuscript, 2005. Disponível em: http://www.michielse.com/files/mcintyre_intl_cooperation.pdf. Acesso em: 03 mai. 2010.

MELlO, Celso D. de Albuquerque. Direito Internacional da Integração. Rio de Janeiro: Renovar, 1996.

MOLINA, Pedro M. Herrera. Convenios de Doble Imposición y Derecho Comunitário. Madri: Ministerio de Economía y Hacienda - Instituto de Estudios Fiscales, 2009.

MOROSINI, Fabio. Globalização e Novas Tendências em Filosofia do Direito Internacional: a Dicotomia entre Público e Privado da Cláusula de Estabilização. In: MARQUES, Cláudia Lima; ARAUJO, Nadia de Araujo (Org.). O Novo Direito Internacional - Estudos em Homenagem a Erik Jayme. Rio de Janeiro: Renovar, 2005.

NABAIS, José Casalta O Dever Fundamental de Pagar Impostos. Coimbra: Almedina, 2004.

RAAD, Kees Van. Introduction OECD Model Commentaries 2008. In Materials on International \& EC Tax Law 2009/2010 (9a. ed. - vol. 1.). Rotterdam: International Tax Center Leiden, 2009.

REZEK, José Francisco. Direito Internacional Público: Curso Elementar. São Paulo: Saraiva, 2002.

SACHETO, Claudio. Las Fuentes del Derecho Internacional Tributario. In: UCKMAR, Victor (Org.). Curso de Derecho Tributario Internacional. Bogotá: Temis, 2003.

SCHOUERI, Luís Eduardo. Preços de Transferência no Direito Tributário Brasileiro (2a ed.). São Paulo: Dialética, 2006.

SCHWARZENBERGER, Georg. International Law and Order. Nova Iorque: Praeger Publishers, 1971.

TENÓRIO, Oscar. Direito Internacional Privado ( $11^{\mathrm{a}}$ ed.). Rio de Janeiro: Freitas Bastos, 1976.

The UN is failing on international tax - so the OECD calls the shots. Disponível em: $<$ http://taxjustice.blogspot.com/2008/06/un-is-failing-on-international-tax-so.html >. Acesso em 03 fev. 2010.

TORRES, Heleno Taveira. Pluritributação Internacional sobre as Rendas de Empresas (2a ed.). São Paulo: RT, 2001. 
TRINDADE, Antônio Augusto Cançado. Direito das Organizações Internacionais ( $3^{\mathrm{a}}$ ed.). Belo Horizonte: Del Rey, 2003, p. 39

UCKMAR, Victor. Introduzione. In: Victor Ukmar (Org.). Corso Di Diritto Tributario Internazionale. Verona: Cedam-Padova, 2000.

. I Tratati Internazionali in Materia Tributaria. In: UCKMAR, Victor

(Org.). Corso di Diritto Tributario Internazionale. Verona: Cedam-Padova, 2000.

VOGEL, Klaus. Importância do Direito Tributário Internacional para os Países em Desenvolvimento. In TAVOLARO, Agostinho Toffoli; MACHADO, Brandão; MARTINS, Ives Gandra da Silva (Org.). Estudos em Homenagem a Gilberto de Ulhôa Canto. Rio de Janeiro: Forense, 1998.

. Klaus Vogel on Double Taxation Conventions: a Commentary to the OECD-, UM- and US Model Conventions for de Avoidance of Doublé Taxation if Income and Capital with Particular Reference to German Treaty Practice. Deventer: Kluwer Law and Taxation Publishers, 1991.

XAVIER, Alberto. Direito Tributário Internacional do Brasil (6 ${ }^{\mathrm{a}}$ ed.). Rio de Janeiro: Forense, 2004.

\section{Sítios visitados (por data):}

$<$ http://taxjustice.blogspot.com/2008/06/un-is-failing-on-international-tax-so.html $>$. Acesso em 03 fev. 2010.

<http://www.imf.org/external/np/fad/itd/2002/031302.htm>. Acesso em: 07 fev. 2010.

$\langle$ http://www.bcb.gov.br/pec/boletim/banual2009/rel2009cap5p.pdf $>$. Acesso em: 18 abr. 2010 .

<http://www.un.org/esa/ffd/tax/overview.htm>. Acesso em 24 abr. 2010.

<http://www.taxjustice.net/cms/upload/pdf/Doha_and_tax_0806_Dries_Lesage.pdf>. Acesso em: 24 abr. 2010.

〈http://www.michielse.com/files/mcintyre_intl_cooperation.pdf $>$. Acesso em: 03 mai. 2010.

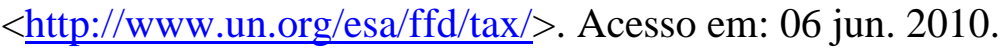

